\title{
VBID, the PPACA, and FREEE Medications: Did Politics Trump the Evidence About Cost Sharing?
}

\author{
Kathleen A. Fairman, MA, and Frederic R. Curtiss, PhD, RPh, CEBS
}

"People in both [the financial markets and baseball] operate with beliefs and biases. To the extent you can eliminate both and replace them with data, you gain a clear advantage... Many people think they are smarter than others in baseball and that the game on the field is simply what they think it is through their set of images/beliefs. Actual data from the market means more than individual perception/belief. The same is true in baseball."

- John Henry, owner of the Boston Red Sox ${ }^{1}$

$\mathrm{I}$ $\mathrm{n}$ his popular book-turned-movie Moneyball, Michael Lewis tells of the historic 2002 season of the Oakland A's, who 1 won more regular-season baseball games than all but 1 other team despite having one of the 2 lowest payrolls. Credit for much of the team's success is due to sportswriter Bill James, who in the 1970s had begun to transform the game by insisting that player-hiring decisions should be based on numerical evidence. Lewis' entertaining account highlights the deficient (yet widely trusted) evidence of playing ability used by baseball talent scouts prior to James' "sustained attack on baseball wisdom"-such as arm strength, psychological attitude, and even facial structure-as well as the remarkable results achieved by James' more empirical methods. On a particularly revealing metric of financial efficiency, marginal expenditures over a $\$ 7$ million minimum common to all teams, the cash-poor Oakland A's paid just $\$ 500,000$ per "win," compared with about $\$ 3$ million for much richer but less successful franchises. James later recalled that he helped Oakland A's general manager Billy Beane to achieve this turnaround by "counting things," or as Lewis describes it, discerning "the game's underlying rationalities ... through statistical analysis." James' passion for the use of data to inform spending decisions was so intense, according to Lewis, that he even avoided talking about certain franchises because he was "unable to suppress his distaste for" the excessive sums expended on suboptimal players by wealthier teams. ${ }^{1}$

The parallels to managed care are obvious. Gut instinct and supposition are not reliable bases on which to make decisions that affect clinical and financial outcomes. Neither is investment of large sums of money in strategies that yield little or no benefit. Those of us working in managed care understand that spending large amounts of money on negligible health care improvement is inappropriate-not because we don't care about patients, but precisely because we do. Specifically, we understand that money spent in one clinical area is unavailable for another. We also understand that funding decisions should be based on valid and reliable evidence to increase the likelihood that we are wisely spending the premium dollars entrusted to us by enrollees, employers, and/or the government.

This fundamental understanding of the need for judicious health care spending highlights the conspicuously ironic title of a recent commentary by proponents of value-based insurance design (VBID), Fendrick et al. (2012): "More Health at Any Price." ${ }^{2}$ The commentary described the rationale and political process underlying the inclusion of provisions for VBID in the Patient Protection and Affordable Care Act (PPACA) of 2010 and observed that, although definitions of VBID and legislative proposals for its use have varied over time, VBID "principles were included in every draft of national health reform legislation."

\section{The PPACA and VBID: Opportunity for Implementation Without a Plan for Evaluation}

An early legislative version of the VBID concept was proposed in the Seniors' Medication Copayment Reduction Act (Hutchison and Stabenow, 2009), which defined VBID as "a methodology for identifying specific medications or classes of medications for which copayments or coinsurance should be reduced or eliminated due to the high value and effectiveness of such medications when prescribed for particular clinical conditions." 3 That bill called for the establishment of "a demonstration program to test [VBID] methodologies for Medicare beneficiaries with chronic conditions."' A later legislative proposal (Baucus, 2009) considerably broadened the concept, defining VBID as a methodology in which "cost-sharing ... is reduced or eliminated to reflect the high value and effectiveness of ... items and services" including "clinically beneficial preventive screenings, lifestyle interventions, medications, immunizations, diagnostic tests and procedures, and treatments." (emphasis added) ${ }^{4}$ The final version of the PPACA stated that the "Secretary [of Health and Human Services] may develop guidelines to permit a group health plan and a health insurance issuer offering group or individual health insurance coverage to utilize value-based insurance designs." ${ }^{5}$ However, unlike the copayment reduction act that had been proposed in 2009, the PPACA did not define "value-based insurance" or call for any evaluation of its efficacy in improving clinical or financial outcomes.

Since then, the concept of VBID has broadened even more substantially, while plans for evaluation remain unspecified. A July 2010 summary of interim final regulations for coverage of preventive services under the PPACA defined VBID as "the provision of information and incentives for consumers 
that promote access to and use of higher value providers, treatments, and services" (emphasis added) and stated that the rules "permit plans and issuers to implement designs that seek to foster better quality and efficiency by allowing cost-sharing for recommended preventive services delivered on an out-ofnetwork basis while eliminating cost-sharing for recommended preventive health services delivered on an in-network basis." 6 A December 2010 "request for information" from several federal agencies including the Department of Health and Human Services (DHHS) sought comments on a wide variety of topics pertaining to the VBID definition and implementation strategies currently in use by insurers but again provided no specific guidance or evaluation research requirements. ${ }^{\top}$

Thus, although Fendrick et al. observed in their commentary that the July 2010 regulations "provide an opportunity to conduct rigorous evaluations of the clinical and economic implications of waiving cost sharing for high value preventive services," ${ }^{2}$ the regulations do not actually contain any specific provisions or standards for evaluation of the strategy. In this respect, the approach taken by DHHS with respect to VBID may be sharply contrasted with the method it used in the Medicare Health Support (MHS) experiment, a rigorous, randomized controlled trial (RCT) of chronic disease management programs for Medicare beneficiaries that was initiated in 2005 and held service vendors financially accountable for their outcomes. ${ }^{8}$ This difference in approach is probably largely attributable to federal responsibility for Medicare costs, but the commentary by Fendrick et al. suggests in addition an active and intentional political process underlying the choice to include VBID in the PPACA: "On advice of Congressional staff, an effort to build a coalition of stakeholders, including labor unions, patient advocacy groups, and payers, was undertaken, as their support was deemed essential before receiving acceptance from policy makers." 2

The lack of a plan for evaluation of VBID makes previous investigations of cost sharing especially important, and Fendrick et al. pointed to "rigorous evaluation" as a factor in the "successful translation of health services research to policy" in the PPACA. ${ }^{2}$ The recent publication of the Post-Myocardial Infarction Free Rx Event and Economic Evaluation (Post-MI FREEE) trial ${ }^{9}$ provides an opportunity for another look at the important question: just how rigorous is the evidence in support of medication copayment reductions or waivers?

\section{Deficient Evidence Base Regarding "Value-Based" Copayment Reductions Prior to Post-MI FREEE}

The core of the argument for VBID is summarized by Fendrick et al. early in their commentary: "Given the abundant evidence that U.S. adults receive only about one half of recommended care and use services of marginal or no benefit, applying clinical nuance to set patients' out-of-pocket costs made sense from clinical and financial perspectives." ${ }^{2}$ On the surface, the argument seems sensible; however, it is a non sequitur case unless evidence shows that cost-sharing amount actually has a clinically meaningful impact on use of services that affect health outcomes.

Proponents of drug copayment reductions and/or waivers have argued that evidence supports this proposition but, as we have observed in a previous evaluation of the quality of the evidence and ethical considerations for VBID, their position is not well-founded. ${ }^{10}$ The RAND Health Insurance Experiment (HIE), an RCT of the effects of insurance design on clinical and financial outcomes during a 3- to 5-year follow-up, showed modest elasticity (price sensitivity), even in response to very high levels of cost sharing for health care services. ${ }^{11,12}$ For example, total annual medical expenses in 1984 dollars were $\$ 518$ for those required to pay nearly all of their medical care costs (95\% cost sharing) compared with $\$ 634$ for those paying $25 \%$ of cost and $\$ 749$ for those receiving free health care, representing arc elasticity values of 0.08 and 0.18 , respectively; and the HIE authors estimated that elasticity in a constant coinsurance system would range from approximately 0.1 to 0.2-far less than the benchmark of 1.00 considered by economists to represent an elastic (i.e., price-sensitive) response. ${ }^{11,13}$ Moreover, despite the HIE authors' assessments that both highand low-value services were affected by cost sharing, free care produced only a few minimal health effects; the most clinically important of these was that diastolic blood pressure was on average 0.9 millimeters of mercury lower in free care than in any cost-sharing condition. ${ }^{11,12}$ In other words, as HIE authors observed following the experiment, cost sharing reduced payers' outlays without affecting patient health, suggesting that for "the kind of people who typically are covered under employer health insurance... there seems to be little cost to increasing cost sharing within the range studied by the experiment and enormous potential savings." 14

In contrast with HIE findings, the evidence underlying copayment reduction/waiver promotion in commercially insured groups has been derived from observational (nonrandomized) research designs ${ }^{15}$ and particularly influential studies have calculated cross-sectional associations of costsharing level with a variety of outcomes, using statistical controls for factors that are measurable using administrative claims data. ${ }^{16,17}$ Study designs of this type are weak because of the likelihood of confounding by unmeasured (and sometimes unmeasurable) factors associated with cost-sharing levels, such as differences in industry sector (e.g., labor union members vs. white- or "pink"-collar sectors of the job market) and organizational culture. Cultural differences that are difficult or impossible to measure but potentially critically important might include, for example, organization-wide cost consciousness or quality-of-care efforts to encourage the use of diet and exercise prior to drug therapy for primary prevention in early-stage conditions (e.g., hypertension, diabetes, dyslipidemia) consistent with clinical practice guidelines. ${ }^{18-20}$ More recent studies of copayment reductions have been 
characterized by deficiencies in design and reporting that we have reviewed in detail previously. ${ }^{10}$

Problems in the Reporting of Observational Evidence. It is notable that the stronger quasi-experimental (pre-intervention vs. post-intervention with comparison group) evidence cited in the commentary by Fendrick et al. was selectively reported. For example, a study by Huskamp et al. (2003) was described as showing that "charging patients more reduced the utilization of high-value services." ${ }^{2}$ However, what the study by Huskamp et al. actually found was that the discontinuation rate for angiotensin-converting enzyme (ACE) inhibitors was significantly lower for patients subject to a cost-sharing increase of $\$ 12$ for prescription drugs (copayment change from $\$ 12$ to $\$ 24$ for nonpreferred brand medications) than for patients who experienced no change to their $\$ 12$ copayment, and discontinuation rates for statins and proton pump inhibitors (PPIs) did not significantly differ between groups. ${ }^{21}$ In the study by Huskamp et al., the only cost-sharing increase that was associated with discontinuation of chronic medication therapy (statins, PPIs, and ACE inhibitors) was an atypically large copayment hike of $\$ 23$, from a flat 1-tier copayment of $\$ 7$ to a $\$ 30$ copayment for nonpreferred brand medications. ${ }^{21}$ This error in describing the results of the study by Huskamp et al. had been made previously in May 2008, in testimony provided to a Congressional House Ways and Means subcommittee regarding the effects of health care cost sharing. ${ }^{22}$

Fendrick et al. also omitted a considerable body of quasiexperimental evidence suggesting little out-of-pocket price responsiveness among commercially insured enrollees. ${ }^{15,23}$ For example, using fixed-effects analysis of longitudinal data for new statin users, Thiebaud et al. (2008) found a decline of $0.9 \%$ in monthly brand drug supply for each $\$ 1$ increase in copayment, or an arc elasticity of about $0.1 .^{24}$ Sedjo and Cox (2008) found that simvastatin users who experienced a copayment decrease because of patent expiration in June 2006 had little change in medication possession ratio (MPR; i.e., + 0.52 percentage points in intervention group vs. -2.02 percentage points in comparison group of other brand statin users) and displayed price elasticity of -0.02 (i.e., zero price sensitivity) in response to copayment decreases of more than $\$ 15 .{ }^{25}$ In a large-sample ( $\mathrm{n}=$ approximately 600,000 enrollees) study of cost-sharing changes in 12 health plans, Landon et al. (2007) also found only modest price responses. ${ }^{26}$ For example, relative to a group whose copayments remained unchanged at $\$ 5$ for all drugs, a plan that changed from a flat $\$ 5$ copayment to a 3 -tier $(\$ 5 / \$ 10 / \$ 25)$ benefit design reduced its total drug spending by $\$ 3.50$ per member per month (pre- vs. post-intervention increases from $\$ 27.40$ to $\$ 30.70$ intervention group vs. from $\$ 28.70$ to $\$ 35.40$ comparison group). Notably, Landon et al. contrasted their findings with those of analyses using weaker methods, observing that one of the most commonly cited studies ${ }^{17}$ "did not follow a population that changed benefits, but rather inferred changes in spending based on cross-sectional analyses, which creates the possibility of bias because of problems controlling for all potential confounding variables." 26 Consistent with these results, our review of more recent copayment reduction/waiver studies, including those published in a November 2010 health policy journal issue devoted to the topic of VBID, found that the methodologically strongest observational work indicates an MPR effect size of only 1.8 to 3.1 percentage points for statins, or approximately 7 to 11 added days of therapy per year, on average..$^{10}$

The selective reporting in VBID research results is not limited to published studies; it extends to failure to complete and/ or publish research projects. Fendrick et al. observed in their commentary that the "acceptance" of the purported relationship between cost sharing and use of "high-value services enabled the implementation of [VBID] demonstration projects that allowed the opportunity to prove the hypothesis that removing financial barriers would enhance their use." ${ }^{2}$ They did not mention that the results of key projects have, unfortunately, gone unreported. As we have pointed out previously, ${ }^{10}$ these include the MHealthy University of Michigan Focus on Diabetes project, which was scheduled for completion 3 years ago but reported only in a poster abstract that described results for only the first year of the 30-month intervention, ${ }^{10,27}$ and the medical utilization findings from a sample studied by Chernew et al., who in 2008 reported MPR increases of 2.6 to 4.0 percentage points ${ }^{28}$ (i.e., 9 to 15 additional days of therapy per year, on average) associated with large drug cost-sharing decreases (from $\$ 5 / \$ 25 / \$ 45$ to $\$ 0 / \$ 12.50 / \$ 22.50$ for generic, preferred brand, and nonpreferred brand, respectively) but who reported only a pharmacoeconomic analysis of projected medical cost outcomes rather than actual medical utilization data for the sample. ${ }^{29}$

Lack of Transparency in Disclosure of Funding. The recent commentary by Fendrick et al. reported that its authors had "no financial conflicts or funding for the manuscript." Because the Center for VBID, which employs all 3 of the commentary's authors, receives financial support from 9 pharmaceutical manufacturers and 1 device manufacturer, ${ }^{30}$ this financial disclosure statement is inconsistent with the guidance of the International Committee of Medical Journal Editors (ICMJE). Specifically, the ICMJE calls for disclosure of "financial relationships with entities in the bio-medical arena that could be perceived to influence, or that give the appearance of potentially influencing, what you wrote in the submitted work... [including] all monies from sources with relevance to the submitted work, not just monies from the entity that sponsored the research." ${ }^{31}$ This departure from ICMJE guidance does not represent the first incident of this type in the pharmacy VBID literature. ${ }^{32,33}$ Although the Center for VBID is to be commended for the transparency of financial disclosure on its website, this level of transparency should be made available to 
readers of journal articles. Potential financial conflicts of interest certainly do not invalidate opinions or research findings, but readers have a right to know about them.

\section{The Importance of Post-MI FREEE}

What this history means for managed care decision makers is that despite heavy promotion by VBID proponents and extensive popular press coverage, there is little published highquality information about the effects of copayment reductions or waivers. Additionally, although compelling because of its strong methodology, the RAND HIE is now several decades old, and its results may not reflect the outcomes of current medical practice standards.

For these reasons, the recently published Post-MI FREEE study is important. Unlike all other cost-sharing studies except the RAND HIE, the study used a randomized controlled design. ${ }^{9}$ Its report transparently disclosed potential financial conflicts of interest of the investigators that included support from pharmaceutical manufacturers and a managed care organization (MCO) that sells a VBID product. The study's sample comprised a clinically important population, patients recently discharged from an inpatient stay for a myocardial infarction (MI), and it focused on evidence-based drug therapies. As the study rationale was described by the Post-MI FREEE investigators in their 2008 analysis plan: "[Study subjects] have high cardiovascular event rates, and secondary prevention medications for acute MI are clearly efficacious, are substantially underused in part because of cost, and are inexpensive relative to the cost of the events that they are intended to prevent." ${ }^{34}$

Following online publication of the Post-MI FREEE study report in November 2011, popular press coverage was mostly positive but somewhat mixed, suggesting that even its authors differed in their interpretations of its results. ${ }^{35-37}$ On the one hand, the principal investigator suggested in an interview with Family Practice News that the Post-MI FREEE findings so strongly supported copayment waivers that MCOs should consider going a step further and begin paying patients to take their medications: "If you call this value-based insurance, we call that VBI 2.0. It's the next innovation. ... From an economic perspective, you could come up with the amount of money that you've saved ... and instead give that [to patients] as a positive incentive." 38 On the other hand, another study investigator lamented to an Associated Press reporter that "we gave these people the medicines for free and only half took it," ${ }^{\prime 37}$ probably referring to the Post-MI FREEE finding that mean MPR for the study drugs was only $43.9 \%$ in an intervention group that was provided with medication at no out-of-pocket cost.

As is true of most research evidence, the truth lies in the details. Only a close look at the methods and findings reveals the likely implications of Post-MI FREEE. A detailed assessment of the study, not feasible in popular press coverage, suggests that payers should be cautious about implementing medication copayment waivers or reductions based on Post-MI
FREEE for 2 reasons. First, the methods on which the study report was based differed in important respects from the 2008 a priori analysis plan and for this reason do not represent outcomes that are of the greatest interest to payers. Second, even if the evidence remains consistent when and if it is more thoroughly reported, it suggests that the effects of copayment waivers/reductions are so negligible that-in Bill James' stylemanaged care decision makers seeking to increase medication adherence should consider putting their money elsewhere.

\section{Post-MI FREEE Critical Appraisal}

The Post-MI FREEE investigators, Choudhry et al., used block randomization at the plan level to study patients discharged from hospital after MI. After the health plans were grouped into blocks representing baseline drug copayment levels and employer scope ("nationally based," defined as a "Fortune 500 company with more than 3,000 employees or a governmental plan sponsor"), they were randomly assigned to a full prescription coverage group that received free post-MI medications (ACE inhibitors or angiotensin II receptor blockers [ARBs], statins, and beta-blockers) or to usual prescription coverage at monthly copayments (measured pre-randomization) of approximately $\$ 51$ for all 3 drugs combined. Randomization occurred a median of 49 days after discharge, but $5 \%$ of study subjects were randomized more than 100 days after discharge. ${ }^{9}$ The primary endpoint outcome was the occurrence of at least 1 readmission for a major vascular event (MI, unstable angina, stroke, congestive heart failure, or inpatient death due to cardiovascular causes) or for revascularization.

During a median (interquartile range) of 394 (201-663) days of follow-up, patients enrolled in plans randomized to full coverage ( $n=2,845$ patients in 1,494 health plans) were not significantly less likely to experience the primary study outcome compared with usual-coverage patients $(n=3,010$ patients in 1,486 health plans; rates of 17.6 and 18.8 per 100 person-years, respectively, $P=0.21$ ). However, the rate of major vascular events or revascularization (i.e., counting multiple types of events rather than just the occurrence of at least 1 event), a secondary outcome, was slightly lower for the fullcoverage group than the usual-coverage group (21.5 vs. 23.3 per 100 person-years, respectively, $P=0.03$ ).

MPRs for each of the 3 therapy classes and for study drugs overall were modestly but significantly $(P<0.001)$ higher in the full-coverage group, with mean differences ranging from 4.4 percentage points for beta-blockers $(49.3 \%$ vs. $45.0 \%$, respectively) to 6.2 percentage points for statins $(55.1 \%$ vs. $49.0 \%$, respectively), ${ }^{9}$ or an average of 16 to 23 additional days of therapy per year. However, a remarkably low $12.1 \%$ of patients in the full-coverage group, compared with $8.9 \%$ of patients in the usual-coverage group, were fully adherent (MPR of at least $80 \%$ ) to all 3 medication classes throughout the 13-month (median) follow-up $(P<0.001)$. 
Through follow-up, neither total medical nor cardiovascular-related medical spending was significantly affected by the intervention $(P=0.72$ and 0.06 , respectively), although costs trended higher in the usual-coverage group (e.g., mean cardiovascular-related medical spending of $\$ 15,661$ vs. $\$ 17,750$ for the full-coverage and usual-coverage groups, respectively). Although full coverage increased the insurer's costs for prescription drugs, as expected (e.g., mean payer cardiovascular drug spending of $\$ 2,271$ compared with $\$ 1,822$ in the usualcoverage group, $P<0.001)$, the between-group differences in the insurer's total outlays were not significant (e.g., mean cardiovascular medical+drug spending of $\$ 17,729$ and $\$ 19,338$ in the full-coverage and usual-coverage groups, respectively, $P=0.14$ ).

In discussing the low rate of medication adherence for the sample overall, Choudhry et al. appropriately suggested that "interventions to address other contributors to nonadherence (e.g., knowledge, attitudes, the complexity of prescribed regimens, and difficulties that patients have in accessing their medications) will be necessary to adequately address [the nonadherence] problem." However, they argued that their results supported the increased use of VBID: "An intervention that reduces patients' financial burdens without changing overall spending and with possible clinical benefits is a rarity in health care and suggests that eliminating cost sharing for secondary prevention after myocardial infarction may be cost-effective." ${ }^{\prime}$

\section{Results for Post-MI FREEE A Priori Sampling Design Not Reported}

For any managed care decision maker considering policy changes that incorporate the results of a recent study report, a key question is external validity, that is, the degree to which the study's methods adequately represent the patient population and circumstances in which its results are likely to be applied. A necessary but problematic methodological adjustment made in the Post-MI FREEE study raises concerns about its external validity for MCOs, and the data necessary to address the problem were apparently available but not reported.

Specifically, patients in post-MI FREEE were followed from randomization to the earlier of loss of insurance eligibility, death, or the end of the study period on November 30, 2010.9 The a priori study plan called for a 1.5-year recruitment period and follow-up of all patients for a minimum of 1 year, a clearly appropriate time frame given typical reporting of 12-month adherence outcomes, as well as the standard consideration of 12-month time horizons by insurers. However, because of "slower-than-anticipated enrollment," the trial's independent data and safety monitoring committee recommended changes to the protocol that were accepted by its steering committee, resulting in extension of the recruitment period by 15 months and a decrease in the minimum follow-up to 3 months. ${ }^{9}$

To determine if this unavoidable protocol change had an effect on study findings, a reasonable methodological approach would be to conduct sensitivity analyses limited to patients who met the originally planned sampling criterion of a minimum 12-month follow-up time, provided that subgroup sample size was sufficient to do so. However, although approximately $65 \%$ of the sample (i.e., about 3,800 patients) met the a priori 12 -month criterion, no sensitivity analyses of this group were performed. ${ }^{39}$

This decision should be viewed as problematic for 3 reasons. First, previous longitudinal studies of statin adherence have suggested that, although the greatest proportion of nonadherence occurs in the first 3 months of treatment, a large proportion occurs after that point. For example, Benner et al. (2002) studied statin adherence measured as proportion of days covered (PDC) in a sample of beneficiaries aged 65 years or older in the New Jersey Medicaid and Pharmaceutical Assistance to the Aged and Disabled programs $(n=34,501)$, finding PDC rates of $79 \%, 56 \%$, and $50 \%$ in the first, second, and fourth quarters of treatment, respectively. ${ }^{40}$ Foody et al. (2008) measured statin persistence rates for new users aged 18 years or older in a large national database; median simvastatin persistence rates were 157 days in primary prevention (no previous cardiovascular events, $n=45,558)$ and 181 days in secondary prevention $(n=4,443) .{ }^{41}$ One would expect that "sticker shock" for brand drugs would be more likely to occur in the early months of therapy and that, as time progresses, more common reasons for nonadherence-for example, forgetfulness, lack of a routine or reminder system for taking medication, concerns about side effects, regimen complexity, beliefs about medications, insufficient information about treatment, and emotional issues - ${ }^{42-47}$ would become more important, thereby potentially further diminishing the already-small effects of the Post-MI FREEE intervention.

Second, a follow-up period of less than 1 year is unlikely to be substantively meaningful either from a clinical perspective or in light of the purpose of VBID. For example, a 2007 metaanalysis of the longitudinal benefit of statin therapy initiated within 12 days of "hospital presentation" for acute coronary syndrome ( $n=9,553$ patients) found that the "benefit of early initiation of statin therapy during acute coronary syndromes slowly accrues over time so that a survival advantage is seen [at] around 24 months." 48 And, as Choudhry et al. observed in the Post-MI FREEE study report, the purpose of VBID is "to increase long-term medication use;" "thus, a 3-month followup is insufficient to inform decision makers about whether the effects of cost-sharing reductions persist for a time period sufficiently long to justify investing financially in them.

Third, the online appendix to the Post-MI FREEE study report includes the results of 13 apparently post hoc (i.e., not mentioned in the original analysis plan) analyses of 28 patient subgroups with a minimum $\mathrm{n}$ of $840 .{ }^{9,34}$ Why the authors chose not to assess results for a large subgroup that represents the a priori sampling plan is unclear. 


\section{Important Pre-Specified Post-MI FREEE Outcomes Not Yet Reported}

Several secondary endpoint outcomes that were included in the Post-MI FREEE analysis plan $^{34}$ are not included in the study report. ${ }^{9}$ These include annual rates of physician visits, emergency department admissions, and hospitalizations. Also unreported is the pre-specified secondary outcome for "the primary outcome including rates of outpatient cardiac death as assessed with the Center for Disease Control's National Death Index." ${ }^{34}$ In response to our queries, the authors responded that (a) the utilization outcomes will be reported soon, and (b) the out-ofhospital death data are subject to a 1.5- to 2-year time lag and are therefore not yet available. ${ }^{39}$

Reporting of the 6 utilization outcomes ( 3 outcomes reported separately for cardiovascular and all-cause) is critically important to MCO decision makers seeking to interpret and apply the results of Post-MI FREEE, for several reasons. First, the block-randomization procedure did not account for reimbursement rates to medical service providers. Thus, despite the randomized design, it is possible that 1 or more health plans with especially high or low levels of reimbursement for the same medical services could affect the cost results even if medical utilization outcomes in the study groups were similar. Second, health plans need annual utilization data, not just cost data for a variable-length follow-up period, to calculate estimates of the likely 12-month impact of interventions in their own plans. Third and related, the Post-MI FREEE report includes no baseline (pre-intervention) values for any of the study outcomes (e.g., health care costs, physician office and emergency department visits, hospitalizations). In addition to informing the question of whether medical service reimbursement levels were comparable between groups, these baseline measures would have provided valuable information to MCOs. For example, the MHS evaluation report by McCall and Cromwell (2011) included baseline values for the outcome variables including utilization, cost, and process of care; this reporting method enabled the investigators (and readers) to assess the improvements in study measures relative to the cost of the intervention. ${ }^{49}$

\section{Nonequivalent Recruitment Materials}

For reasons not explained in the Post-MI FREEE report, the recruitment letters for the full-coverage and usual-coverage groups (contained in an online report appendix) differed in important ways. First, the usual-coverage group letter contained a list of lifestyle recommendations from the American Heart Association, including regular physical activity, healthy weight maintenance, and limited alcohol intake, which did not appear in the full-coverage recruitment letters. Second, in describing "medicines to keep your heart strong," text that appeared in both letters, the usual-coverage group letter included the additional statement: "You may be on some medications for many years..." This departure from the general principle of equivalent conditions except for the intervention was unfortunate and could have affected the study outcome.

\section{No Information About Generic Drug Utilization}

Although not included in the pre-specified analysis plan, the generic dispensing ratio (GDR) is an essential metric for managed care pharmacy that should have been an outcome measure in Post-MI FREEE. Whether providing free brand-name medication discourages therapeutically appropriate generic drug substitution is a critically important policy question that has not yet been investigated in VBID research. ${ }^{10}$ Generic drug use has important economic implications; for example, a recent analysis of 2008 Medicare Part D prescription drug plan (PDP) data for drugs overall, statins, ACE inhibitors/ARBs, and antidepressants (selective-serotonin reuptake inhibitors [SSRIs] and selective-norepinephrine reuptake inhibitors [SNRIs]) found that $75.9 \%$ of regional variation in overall per capita pharmaceutical spending was attributable to cost per prescription rather than to utilization rates..$^{50}$ The correlation coefficient for the relationship of GDR with cost per prescription was 85\% overall and exceeded $88 \%$ in all 3 therapy classes, and the authors estimated that the Medicare program would have saved approximately $10 \%$ on prescription drug costs, an estimated $\$ 4.5$ billion, had the bottom 4 quintiles of generic drug use achieved the GDR of the top quintile. ${ }^{50}$ As important as these economic implications are, the clinical implications should not be overlooked. As we have observed previously, benefit design policies that encourage generic drug use often direct beneficiaries to medications with a longer safety track record. ${ }^{51,52}$

\section{Modest Adherence Improvements in Post-MI FREEE Are Consistent with Other Research}

The underwhelming effects of cost-sharing reduction in Post-MI FREEE relative to the size of the nonadherence problem observed in the sample are unsurprising given the results of other research. For example, in testing various models to predict adherence among 14,257 commercially insured patients initiating statin treatment, Chan et al. (2010) found that a model containing copayment data without other covariates produced a c-statistic of $0.543,,^{53}$ (where 0.50 indicates predictive ability equivalent to random assignment and 1.00 indicates perfect prediction),${ }^{54}$ suggesting that copayment information gives one no better chance than a coin toss of predicting adherence behavior. In a study of 229,918 adult enrollees in an Israeli health maintenance organization, Chodick et al. (2008) found that $75 \%$ or more of patients in both primary and secondary prevention discontinued statin treatment within 2 years after treatment initiation despite "low out-of-pocket prescription costs and free access to health services." 55 Analyses of interaction terms in Post-MI FREEE found that the relationship between the intervention and the primary endpoint outcome did not significantly vary by the baseline (pre-intervention) 
cost-sharing amount for all study drugs combined (e.g., "low" copayment $[$ mean $=\$ 32.48] \mathrm{OR}=0.91,95 \% \mathrm{CI}=0.73-1.15$ vs. "high" copayment [mean $=\$ 54.03] \mathrm{OR}=0.97,95 \% \mathrm{CI}=0.68$ 1.39). In other words, as Choudhry et al. observed, response to free medication was unrelated to the degree of change in out-of-pocket cost share. ${ }^{9}$

Two studies published in this issue of JMCP provide additional information about the relationship between benefit design and medication adherence. Jung et al. used Medicare Part D prescription drug event files to measure statin adherence, comparing matched samples of patients in PDPs versus Medicare Advantage Prescription Drug (MA-PD) plans ( $n=76,922$ in each group). ${ }^{56}$ The authors hypothesized that because MA-PD plans are responsible both for medical and prescription drug costs, whereas PDPs provide prescription drugs only, MA-PD plans would have more incentive to provide generous drug benefits, thereby improving adherence and reducing medical cost outlays. Although the authors did not measure actual cost-sharing amounts paid by the patients in their sample, they provided evidence from the Medicare Payment Advisory Commission indicating that MA-PD plans do, on average, offer much more generous prescription drug benefits; for example in 2007, 75\% of MA-PD plans versus 48\% of PDPs offered an "enhanced" benefit, and 90\% of MA-PD plans versus $60 \%$ of PDPs charged no deductibles ${ }^{57}$ However, Jung et al. found only a slight and clinically unimportant between-group difference in MPR, 1.36 percentage points, representing only 5 additional days of statin therapy per year, on average (MPR $=70.8 \%$ MA-PD vs. $69.4 \%$ PDP, $P<0.001$ ).

In the second study in this issue of JMCP, Johnston et al. found similarly modest but potentially more clinically significant effects of high cost-sharing amounts in their panel data analysis of 3,731 ( $\mathrm{n}=19,199$ patient-quarters) commercially insured patients with human immunodeficiency virus (HIV) who initiated combination antiretroviral treatment (cART) during a 5-year time frame beginning in January 2003. ${ }^{58}$ Although mean cART MPR differed very little for patients in the bottom and top cost-sharing quintiles ( $97.2 \%$ vs. $94.0 \%$, respectively) despite remarkably large out-of-pocket cost differences $(\$ 0-\$ 20$ vs. $\$ 84-\$ 3,832$ per 30 -day supply, respectively), the predicted mean adherence rates at various cost-sharing levels suggested potentially clinically significant effects. In the second quarter of follow-up after cART initiation, the predicted probability of $95 \%$ adherence was $78.2 \%$ for patients paying $\$ 25$ per month (25th cost-sharing percentile) compared with $75.2 \%$ for patients paying $\$ 144$ per month (90th cost-sharing percentile). In the seventh quarter of follow-up, the predicted probabilities of $95 \%$ adherence for $\$ 25$ and $\$ 144$ cost-sharing amounts were $77.3 \%$ and $70.7 \%$, respectively. These findings suggest decreases in adherence of approximately $3.8 \%$ in the second quarter and $8.5 \%$ in the seventh quarter of cART in response to a $476 \%$ increase in cost-sharing amount.
Two important caveats about the report by Johnston et al should be noted. First, attrition bias is a concern; for example, during the seventh quarter of cART, only $25 \%$ of the sample cases remained under observation. Second, although the 95\% adherence standard is commonly used and is recommended by the World Health Organization, ${ }^{59}$ the research cited by Johnston et al. points to a much lower clinically meaningful standard of $78 \%$ for the cART regimens included in the study. Using the $78 \%$ standard, the between-group differences are smaller.

Despite those caveats, the work of Johnston et al. reminds us of important points that were originally raised in a study by Gleason et al. (2009) of the relationship between cost sharing (for 30-day or 90-day supplies, with 30-day claims constituting $71 \%$ of the sample) and "abandonment" of (failure to pick up) new prescriptions for tumor necrosis factor (TNF) blockers and injectable medications for multiple sclerosis (MS) ${ }^{60}$ Gleason et al. found that the MS prescription abandonment rate was $5.7 \%$ for the $82.5 \%$ of newly initiating patients $(n=2,303)$ whose cost-sharing amount was $\$ 0-\$ 100$ but increased to onequarter of claims or more for the $13.8 \%$ of patients $(n=384)$ whose cost-sharing amount was more than $\$ 200$ per claim. For TNF blockers, the findings were similar, although the threshold at which the abandonment rate increased was lower; the abandonment rate was $4.7 \%$ for the $83.7 \%$ of newly initiating patients $(n=6,123)$ whose out-of-pocket cost was $\$ 0$ - $\$ 100$, ranged from $11 \%-16 \%$ for the $10.6 \%$ of patients $(n=774)$ with an out-of-pocket cost from $\$ 101-\$ 500$, and was $26.4 \%$ for the $5.7 \%$ of patients $(n=416)$ whose out-of-pocket cost was more than $\$ 500 .{ }^{60}$

Thus, like the work of Gleason et al., the study of patients with HIV by Johnston et al. suggests that high cost-sharing amounts for specialty medications are atypical, affecting approximately $10 \%-20 \%$ of patients, and their associations with medication adherence are small relative to the amount of cost-sharing change. However, they are potentially clinically problematic when regimens are specialized and no generic alternatives are available.

\section{How Much Benefit for How Much Cost?}

For an MCO decision maker, the key benefit design question is not whether to implement every intervention that creates a statistically significant effect in a research study-such an approach would be unwise today, when large sample sizes commonly make clinically meaningless differences statistically significant. The question is which interventions produce improvements in health outcomes that are both meaningful and financially sustainable. In other words, the fact that an intervention produces a statistically significant outcome in a study does not make it a wise investment if other interventions produce better (i.e., larger and/or more clinically meaningful) outcomes, especially if they do so at a lower cost. An editorial accompanying the publication of the Post-MI FREEE results 
described the effects of the full-coverage intervention as "distressingly modest." ${ }^{61}$ However, a key question in translating its results into policy is whether any other options exist to increase adherence by the same or greater amount at equal or lower cost.

Although a thorough assessment of the current state of adherence research is beyond the scope of this editorial, recently published RCTs shed light on this question and suggest the possibility of less expensive, equally or more effective alternatives to providing free medication. For example, Bender et al. (2010) randomized 50 adult (aged 18 to 65 years) patients with asthma and a corticosteroid prescription to usual care (baseline and follow-up visit 10 weeks apart) or intervention (usual care visits plus 2 interactive voice response [IVR] educational telephone calls, with an additional IVR call for patients who "reported recent symptoms of poorly controlled disease or failure to fill a prescription"). ${ }^{62}$ All patients in both groups received $\$ 25$ for participation in each visit. Corticosteroid adherence rates, measured using electronic tracking devices attached to inhalers or changes in canister weights (depending on the product), were $64.5 \%$ in the IVR group and $49.1 \%$ in the control group $(P=0.003)$. However, between-group differences in asthma control rates, as measured by the Asthma Quality of Life Questionnaire and Asthma Control test, were not significant. ${ }^{62}$

In a second RCT, Simon et al. (2011) evaluated the use of online messaging in 208 patients treated for depression in 9 primary care clinics; patients were randomized to 3 online contacts with a psychiatric nurse or to usual primary care. ${ }^{63}$ At 3 months follow-up, antidepressant adherence rates were $81 \%$ in the messaging group compared with $61 \%$ in usual care $(P=0.001)$; depression symptoms as measured by a symptom checklist were also significantly better ( 0.95 vs. 1.17 , respectively, $P=0.043) .{ }^{63}$ In a randomized controlled assessment of IVR technology coupled with educational feedback tailored to address patient-reported knowledge level, attitudes, and barriers to medication adherence, Stacy et al. (2009) achieved improvements in statin adherence rates measured by " 6 -month point prevalence" of use (70.4\% for the intervention vs. $60.7 \%$ for the control group, $P<0.05) .{ }^{64}$ However, the sample was limited to patients who initially gave consent to the study via IVR and therefore may have been especially receptive to IVR messaging.

It is notable that the interventions in all 3 of these studies achieved adherence results better-some far better-than those observed in Post-MI FREEE. Because providing free medication does nothing to address key drivers of nonadherence, especially forgetfulness (often due to regimen complexity) and concerns about the benefits relative to the risks of treatment-both of which can be addressed with communication technologies-this result is unsurprising. Although none of the studies reported the costs of the interventions, they all used relatively inexpensive communication vehicles that were probably lower-cost than the $\$ 50$ per patient per month spent in the Post-MI FREEE trial. A scoring algorithm developed by McHorney (2009) to predict risk of nonadherence based on logistic regression analysis of survey data suggests communication content that might be especially helpful. ${ }^{65}$ Scoring weights were 20 and 14 for beliefs that the prescribed drug is unnecessary and may "do more harm than good," respectively, and only 2 for financial burden due to out-of-pocket cost. ${ }^{65}$

\section{More Health? At Any Price?}

No one can argue against the obvious propositions that decisions about health care should be based on clinical value and that encouraging adherence to medications is desirable. The question is not whether these are worthwhile goals; it is how to spend resources wisely to achieve them. As one health care methodologist recently observed in commenting on the proposal that patients should be paid to take cardiovascular drugs because of the Post-MI FREEE findings, "one has to wonder: if 'free' is not powerful enough to change behavior, is 'more free' where we need to go?" 66

The evidence available to date suggests that copayment reductions/waivers provided to commercially insured populations, especially when applied in primary prevention and/or to brand drugs in therapy classes with generic alternatives, are unlikely to yield meaningful health improvements and may direct scarce resources away from financing therapy areas in which patients have no generic alternatives, such as biopharmaceuticals. As we have observed previously, the slow uptake of copayment reduction/waiver strategies among private payers is appropriate. ${ }^{10}$ Although Post-MI FREEE certainly represented a major step forward in a research field littered with studies that are weakly designed and/or nontransparently reported, its results suggest the need for continued caution in VBID adoption. Until utilization analyses are reported, the Post-MI FREEE results have limited applicability to MCO costs, and even when fully reported, the Post-MI FREEE results should not be applied to primary prevention.

Thus, it is unfortunate that Congress included VBID in the PPACA before it had the evidence necessary to make an informed decision, although as translated into rule to date, the concept has been so broadened as to be nearly unrecognizable. This haphazard approach, akin to baseball hiring practices before Bill James, should be benched and replaced by the strategy that the federal government used in making a decision about disease management for chronic conditions in Medicare beneficiaries: (a) subject copayment waivers/reductions to an RCT for a time period that is of sufficient duration to measure the study outcomes adequately and (b) hold vendors financially accountable for the results that they produce. Private payers should insist on the same arrangement or, if possible, should conduct their own randomized evaluations of VBID. Only after tests of this kind will we know whether copayment reductions are a reasonably effective use of public or private funds. 


\section{Authors}

KATHLEEN A. FAIRMAN, MA, is Associate Editor and Senior Methodology Reviewer, and FREDERIC R. CURTISS, PhD, RPh, CEBS, is Editor-in-Chief of the Journal of Managed Care Pharmacy.

AUTHOR CORRESPONDENCE: Kathleen A. Fairman, MA, Academy of Managed Care Pharmacy, 100 North Pitt St., Suite 400, Alexandria, VA 22314. Tel.: 602.867.1343;

E-mail:kfairman@amcp.org.

\section{DISCLOSURES}

The authors report no financial conflicts of interest related to the subjects or products discussed in this article.

\section{REFERENCES}

1. Lewis M. Moneyball: The Art of Winning an Unfair Game. New York, NY: W.W. Norton and Company; 2004.

2. Fendrick AM, Martin JJ, Weiss AE. Value-based insurance design: more health at any price. Health Serv Res. 2012;47(1 Pt 2):404-13.

3. 111th Congress (2009-2010)—S. 1040. Govtrack.US. May 14, 2009. Available at: http://www.govtrack.us/congress/billtext.xpd?bill=s111-1040. Accessed February 14, 2012

4. 11lth Congress (2009-2010)—S. 1796. Govtrack.US. October 19, 2009. Available at: http://www.govtrack.us/congress/bill.xpd?bill=sll1-1796. Accessed February 14, 2012

5. 11lth Congress of the United States of America. An act entitled the Patient Protection and Affordable Care Act. April 23, 2010. Available at: http://www.gpo.gov/fdsys/pkg/PLAW-11lpubll48/pdf/PLAW-11lpubll48. pdf. Accessed February 10, 2012

6. Overview of the regulations: PHS Act Section 2713, coverage of preventive health services. Federal Register. July 19, 2010;75(137). Available at: http://edocket.access.gpo.gov/2010/pdf/2010-17242.pdf. Accessed February 10, 2012.

7. Request for information regarding value-based insurance design in connection with preventive care benefits. Federal Register. December 28 , 2010;75(248). Available at: http://webapps.dol.gov/federalregister/PdfDisplay. aspx?DocId=24556. Accessed February 10, 2012.

8. Cromwell J, McCall N, Burton J. Evaluation of Medicare Health Support chronic disease pilot program. Health Care Financ Rev. 2008;30(1):47-60.

9. Choudhry NK, Avorn J, Glynn RJ, et al.; Post-Myocardial Infarction Free Rx Event and Economic Evaluation (MI FREEE) Trial. Full coverage for preventive medications after myocardial infarction. N Engl J Med. 2011; 365(22):2088-97.

10. Fairman KA, Curtiss FR. What do we really know about VBID? Quality of the evidence and ethical considerations for health plan sponsors. J Manag Care Pharm. 2011;17(2):156-74. Available at: http://www.amcp.org/data/ jmcp/156-174.pdf.

11. Manning WG, Newhouse JP, Duan N, Keeler EB, Liebowitz A, Marquis MS. Health insurance and the demand for medical care: evidence from a randomized experiment. Am Econ Rev. 1987;77(3):251-77.

12. Keeler EB, Brook RH, Goldberg GA, Kamberg CJ, Newhouse JP. How free care reduced hypertension of participants in the Rand Health Insurance Experiment. October 1985. Available at: http://www.rand.org/pubs/ reports/2009/R3326.pdf. Accessed February 21, 2012.
13. Moffatt M. Price elasticity of demand. About.com. Available at: http:// economics.about.com/cs/micfrohelp/a/priceelasticity.htm. Accessed February 10, 2012.

14. Keeler EB. Effects of cost sharing on use of medical services and health. J Med Pract Manage. 1992;8:317-21. Available at: http://www.rand.org/content/ dam/rand/pubs/reprints/2005/RP1114.pdf. Accessed February 9, 2012.

15. Fairman KA, Curtiss FR. Still looking for health outcomes in all the wrong places? Misinterpreted observational evidence, medication adherence promotion, and value-based insurance design. J Manag Care Pharm. 2009;15(6):501-07. Available at: http://www.amcp.org/WorkArea/ DownloadAsset.aspx?id=8175.

16. Goldman DP, Joyce GF, Escarce JJ, et al. Pharmacy benefits and the use of drugs by the chronically ill. JAMA. 2004:291(19):2344-50. Available at: http://jama.ama-assn.org/content/291/19/2344.long. Accessed February 15, 2012.

17. Joyce GF, Escarce JJ, Solomon MD, Goldman DP. Employer drug benefit plans and spending on prescription drugs. JAMA. 2002;288(14):1733-39. Available at: http://jama.ama-assn.org/content/288/14/1733.long. Accessed February 10, 2012.

18. National Cholesterol Education Program. ATP III guidelines at-a-glance quick desk reference. Available at: http://www.nhlbi.nih.gov/guidelines/cholesterol/atglance.pdf. Accessed February 10, 2012.

19. U.S. Department of Health and Human Services, National High Blood Pressure Education Program. JNC 7 express: The seventh report of the Joint National Committee on Prevention, Detection, Evaluation, and Treatment of High Blood Pressure. August 2004. Available at: http://www.nhlbi.nih.gov/ guidelines/hypertension/express.pdf. Accessed February 10, 2012.

20. Qaseem A, Humphrey LL, Sweet DE, Starkey M, Shekelle P; Clinical Guidelines Committee of the American College of Physicians. Oral pharmacologic treatment of type 2 diabetes mellitus: a clinical practice guideline from the American College of Physicians. Ann Intern Med. 2012;156(3):21831. Available at: http://www.annals.org/content/156/3/218. Accessed February 10, 2012.

21. Huskamp HA, Deverka PA, Epstein AM, Epstein RS, McGuigan KA, Frank RG. The effect of incentive based formularies on prescription-drug utilization and spending. N Engl J Med. 2003;349(23):2224-32. Available at: http://www.nejm.org/doi/pdf/10.1056/NEJMsa030954. Accessed February $10,2012$.

22. Chernew M. Cost sharing in health care markets. Testimony before the Subcommittee on Health of the House Committee on Ways and Means. May 14, 2008. Available at: http://www.sph.umich.edu/vbidcenter/news/pdfs/ Chernew\%20Testimony\%2005-12-08\%20_final.pdf.

23. Fairman KA. The future of prescription drug cost-sharing: real progress or dropped opportunity? J Manag Care Pharm. 2008;14(1):70-82. Available at: http://www.amcp.org/data/jmcp/JMCPMaga_JanFeb\%2008_070-082.pdf.

24. Thiebaud P, Patel VB, Nichol MB. The demand for statin: the effect of copay on utilization and compliance. Health Econ. 2008;17(1):83-97.

25. Sedjo RL, Cox ER. Lowering copayments: impact of simvastatin patent expiration on patient adherence. Am J Manag Care. 2008;14(12):813-18.

26. Landon BE, Rosenthal MB, Normand SL, et al. Incentive formularies and changes in prescription drug spending. Am J Manag Care. 2007;13(6 Pt 2):360-69

27. Rosen AB, Wing J, Herman WH, et al. Impact of a targeted value-based insurance design intervention on adherence to essential secondary prevention medications in diabetes. Poster presented at: 32nd Annual Meeting of the Society of General Internal Medicine; May 13-16, 2009; Miami Beach, FL.

28. Chernew ME, Shah MR, Wegh A, et al. Impact of decreasing copayments on medication adherence within a disease management environment. Health Aff (Millwood). 2008;27(1):103-12.

29. Chernew ME, Juster IA, Shah M, et al. Evidence that value-based insurance can be effective. Health Aff (Millwood). 2010;29(3):530-36. 
30. University of Michigan, Center for Value-Based Insurance Design Funding. Available at: http://www.sph.umich.edu/vbidcenter/about/funding. html. February 10, 2012

31. International Committee of Medical Journal Editors. ICMJE form for disclosure of potential conflicts of interest. Available at: http://www.icmje. org/coi_disclosure.pdf and http://www.icmje.org/ethical_4conflicts.html. Accessed February 10, 2012

32. Chernew W, Fendrick AM. Value and increased cost sharing in the American health care system. Health Serv Res. 2008;43(2):451-57. Available at: http://www.ncbi.nlm.nih.gov/pmc/articles/PMC2442370/?tool=pubmed. Accessed February 12, 2012

33. Fendrick AM, Smith DG, Chernew ME. Applying value-based insurance design to low-value health services. Health Aff (Millwood). 2010;29(11):201721.

34. Choudhry NK, Brennan T, Toscano M, et al. Rationale and design of the Post-MI FREEE trial: a randomized evaluation of first-dollar drug coverage for post-myocardial infarction secondary preventive therapies. Am Heart J. 2008;156(1):31-36. Available at: http://www.ncbi.nlm.nih.gov/pmc/articles/ PMC2697130/?tool=pubmed. Accessed February 6, 2012.

35. Miller R. Cutting copays for post-MI drugs helps outcomes, with no added cost to insurers. Theheart.org. November 14, 2011.

36. Kaiser C. Free MI meds produce mixed bag of results. Medpage Today. November 14, 2011. Available at: http://www.medpagetoday.com/ Cardiology/Prevention/29666. Accessed February 6, 2012.

37. Marchione M. Study finds many patients shun free heart drugs. AP. November 14, 2011. Available at: http://articles.boston.com/2011-11-14/ lifestyle/30398405_1_heart-drugs-medicines-patients. Accessed February 6, 2012

38. Wendling P. Free meds boost post-MI outcomes, rx adherence. Internal Medicine News. November 15, 2011. Available at: http://www.internalmedicinenews.com/news/cardiovascular-disease/single-article/free-meds-boostpost-mi-outcomes-rx-adherence/b3963d4826.html. Accessed February 6, 2012

39. Personal communication, Niteesh Choudhry, MD, PhD. November 28, 2011.

40. Benner JS, Glynn RJ, Mogun H, Neumann PJ, Weinstein MC, Avorn $\mathrm{J}$. Long-term persistence in use of statin therapy in elderly patients. JAMA. 2002;288(4):455-61. Available at: http://jama.ama-assn.org/content/288/4/455.long. Accessed February 6, 2012.

41. Foody JM, Joyce AT, Rudolph AE, Liu LZ, Benner JS. Persistence of atorvastatin and simvastatin among patients with and without prior cardiovascular diseases: a U.S. managed care study. Curr Med Res Opin. 2008;24(7):1987-2000

42. Osterberg L, Blaschke T. Adherence to medication. N Engl J Med. 2005;353(5):487-97.

43. Bermingham M, Hayden J, Dawkins I, et al. Prospective analysis of LDL-C goal achievement and self-reported medication adherence among statin users in primary care. Clin Ther. 2011;33(9):1180-89.

44. Choudhry NK, Fischer MA, Avorn J, et al. The implications of therapeutic complexity on adherence to cardiovascular medications. Arch Intern Med. 2011;171(9):814-22

45. Fung V, Sinclair F, Wang H, Dailey D, Hsu J, Shaber R. Patients' perspectives on nonadherence to statin therapy: a focus-group study. Perm J. 2010;14(1):4-10.

46. Fried TR, Tinetti ME, Towle V, O'Leary JR, Iannone L. Effects of benefits and harms on older persons' willingness to take medication for primary cardiovascular prevention. Arch Intern Med. 2011;171(10):923-28.

47. Nair KV, Belletti DA, Doyle JJ, et al. Understanding barriers to medication adherence in the hypertensive population by evaluating responses to a telephone survey. Patient Prefer Adherence. 2011;5:195-206.
48. Bavry AA, Mood GR, Kumbhani DJ, Borek PP, Askari AT, Bhatt DL. Long-term benefit of statin therapy initiated during hospitalization for an acute coronary syndrome: a systematic review of randomized trials. Am J Cardiovasc Drugs. 2007;7(2):135-41.

49. McCall N, Cromwell J. Results of the Medicare Health Support diseasemanagement pilot program. N Engl J Med. 2011;365(18):1704-12

50. Donohue JM, Morden NE, Gellad WF, et al. Sources of regional variation in Medicare Part D drug spending. N Engl J Med. 2012;366(6):53038. Available at: http://www.nejm.org/doi/full/10.1056/NEJMsal104816. Accessed February 11, 2012.

51. Fairman KA, Curtiss FR. Managed care and health care reform: everything old is new again. J Manag Care Pharm. 2009;15(9):766-75. Available at: http://www.amcp.org/data/jmcp/766-775.pdf

52. Curtiss FR, Fairman KA. Diabetes drug therapy—first, do no harm. J Manag Care Pharm. 2008;14(7):658-60. Available at: http://www.amcp.org/ data/jmcp/658-660_CurtissFairman-Final.pdf.

53. Chan DC, Shrank WH, Cutler D, et al. Patient, physician, and payment predictors of statin adherence. Med Care. 2010;48(3):196-202.

54. Peng CJ, Lee KL, Ingersoll GM. An introduction to logistic regression analysis and reporting. Journal of Educational Research. 2002;96(1):3-14. Available at: http://bit.csc.lsu.edu/ jianhua/emrah.pdf. Accessed February 11,2012

55. Chodick G, Shalev V, Gerber Y, et al. Long-term persistence with statin treatment in a not-for-profit health maintenance organization: a populationbased retrospective cohort study in Israel. Clin Ther. 2008;30(11):2167-79.

56. Jung K, McBean AM, Kim J. Comparison of statin adherence among beneficiaries in MA-PD plans versus PDPs. J Manag Care Pharm. 2012;18(2):10615

57. Medicare Payment Advisory Commission. Report to the Congress: Medicare payment policy. March 2008. Available at: http://www.medpac. gov/documents/Mar08_EntireReport.pdf. Accessed February 11, 2012.

58. Johnston SS, Juday T, Seekins D, Espindle D, Chu B. Association between prescription cost sharing and adherence to initial combination antiretroviral therapy in commercially insured antiretroviral-naive patients with HIV. J Manag Care Pharm. 2012;18(2):129-45.

59. World Health Organization. HIV/AIDS Programme. Antiretroviral therapy for HIV infection in adults and adolescents: recommendations for a public health approach-2006 rev. Available at: www.who.int/hiv/pub/ guidelines/artadultguidelines.pdf. Accessed February 15, 2012.

60. Gleason PP, Starner CI, Gunderson BW, Schafer JA, Sarran HS. Association of prescription abandonment with cost share for high-cost specialty pharmacy medications. J Manag Care Pharm. 2009;15(8):648-58. Available at: http://www.amcp.org/data/jmcp/648-658.pdf.

61. Goldman L, Epstein AM. Improving adherence-money isn't the only thing. N Engl J Med. 2011;365(22):2131-33.

62. Bender BG, Apter A, Bogen DK, et al. Test of an interactive voice response intervention to improve adherence to controller medications in adults with asthma. J Am Board Fam Med. 2010;23(2):159-65. Available at: http://www.jabfm.org/content/23/2/159.long. Accessed February 16, 2012.

63. Simon GE, Ralston JD, Savarino J, Pabiniak C, Wentzel C, Operskalski $\mathrm{BH}$. Randomized trial of depression follow-up care by online messaging. $J$ Gen Intern Med. 2011;26(7):698-704.

64. Stacy JN, Schwartz SM, Ershoff D, Shreve MS. Incorporating tailored interactive patient solutions using interactive voice response technology to improve statin adherence: results of a randomized clinical trial in a managed care setting. Popul Health Manag. 2009;12(5):241-54.

65. McHorney CA. The Adherence Estimator: a brief, proximal screener for patient propensity to adhere to prescription medications for chronic disease. Curr Med Res Opin. 2009;25(1):215-38. 